\title{
Роль импактов в строении континентальной коры раннего докембрия: современные представления
}

\author{
Лобач-Жученко С.Б. ${ }^{1}$, Каулина Т.В. ${ }^{2}$ \\ ${ }^{1}$ Институт геологии и геохронологии докембрия PAH, Санкт-Петербург, Slobach-Zhuchenko@mail.ru \\ ${ }^{2}$ Геологический институт КНЦ РАН, Anamumbl, kaulina@geoksc.apatity.ru
}

Аннотация. Падение астероидов является фундаментальным процессом в солнечной системе и важным инструментом, влияющим на развитие Земли. На основе обзора литературных данных обсуждается влияние импактных процессов на формирование Земной коры на ранних этапах ее развития. Несмотря на мощную метеоритную бомбардировку в архее, в настоящее время известны единичные кратеры докембрийского возраста, поскольку морфологические следы метеоритных ударов практически не сохранились в связи с последующими геологическими событиями. Рассмотрены методы распознавания древних импактных структур на основе геофизических данных и данных о химическом составе пород. Обсуждается роль плюмов в развитии земной коры и их связь с импактными процессами, также рассматриваются дискуссионные вопросы геологии, связанные с составом, временем и механизмом образования континентальной коры.

Ключевые слова: импактные структуры, плюмы, континентальная кора, докембрий.

\section{The role of impacts in the structure of the Early Precambrian continental crust: modern views}

\author{
Lobach-Zhuchenko S.B. ${ }^{1}$, Kaulina T.V. ${ }^{2}$ \\ ${ }^{1}$ Institute of Precambrian geology and geochronology,Sain-Petersburg, Slobach-zhuchenko@mail.ru \\ ${ }^{2}$ Geological Institute of the Kola Science Centre of RAS, Apatity, kaulina@geoksc.apatity.ru
}

\begin{abstract}
The fall of asteroids is a fundamental process in the solar system and an important tool that affects the development of the Earth. Based on a review of literature data, the influence of impact processes on the formation of the Earth's crust at the early stages of its development is discussed. Despite the powerful meteorite bombardment in the Archean time, only several Precambrian craters are known at present, since the morphological traces of meteorite craters were erased with later geological processes. The most useful methods of recognition of ancient impact structures are based on geophysical data and the chemical composition of rocks. The role of plumes in the development of the Earth's crust and their relationship with impact processes are discussed, as well as controversial questions of geology related to the composition, time, and mechanism of the continental crust formation.
\end{abstract}

Key words: impact structures, plumes, continental crust, Precambrian.

«Earth as an Evolving Planetary System»

K.C. Condie

\section{Введение}

Падение астероидов является фундаментальным процессом в солнечной системе и важным инструментом, влияющим на развитие Земли (Reimold, Jourdan, 2012, Кузьмин и др., 2016). О масштабе этого процесса можно судить по каталогу импактных структур с возрастом моложе 2 млрд. лет, где приведены 1082 структуры; около 400 из которых выделены с достаточным обоснованием (Lyapidevskaya, Gusiakov, 2010).

После образования Земли (4.56 млрд. лет назад) в первые 100 млн. лет сформировались $\mathrm{Fe}-\mathrm{Ni}$ ядро, мантия и кора Земли, образовалась Луна. Результаты изучения Луны показали, что аккреция космического материала и активная бомбардировка ее поверхности продолжались после ее отделения, на Земле они были еще более активными. Морфологические следы бомбардировки, имевшие место в первые сотни миллионов лет, на Земле практически не сохранились, что связано с проявлением эндогенных процессов, эрозией поверхности, наложением импактных структур друг на друга в связи с их многочисленностью и большими размерами кратеров. В настоящее время известны единичные импактные кратеры или продукты удара докембрийского возраста: структура Марбл Бар в Западной Австралии, имеющая возраст 3.46 млрд. лет (Glikson et al., 2016), различного возрас- 
та сферулы в осадках кратона Каапвааль в Южной Африке и осадках бассейна Фортескью в Западной Австралии, указывающие на многократность импактных событий в интервале времени от 3.47 до 2.65 млн. лет (например, Byerly et al., 2002); импактная структура Маниитсок в Ю3 Гренландии ( 3 млрд лет - Garde et al., 2012). Несмотря на внимание, уделенное исследователями импактным событиям раннего этапа развития Земли (Koeberl, 2006: Reimold, Gibson, 2006; Glikson, 2013; Кузьмин и др., 2016 и др.), задача влияния древних импактов на происхождение и строение раннедокембрийской коры остается актуальной.

\section{Методы изучения импактов. Критерии}

В результате последних 50-летних исследований установлены геофизические, минералогические, геохимические и структурные критерии ударов метеоритов (Glikson, 2005; Koeberl, 2006; McCall., 2009; Reimold and Jourdan, 2012 и ссылки там). Многие признаки шокового метаморфизма в древних структурах не сохраняются. Для распознавания древних импактов представляют интерес геофизические данные и данные о химическом составе пород. Магнитная съемка обнаруживает в ряде случаев кольцевую структуру под кратерами; некоторые структуры, например Попигайская, характеризуются большой отрицательной гравитационной аномалией (Масайтис и др., 1975). Сейсмические методы демонстрируют существенную перестройку глубинного строения коры, вызываемую ударами астероидов. Так, например, для кратера Чиксулуб (Morgan et al., 2000) установлено поднятие нижней коры и границы Мохо в центре структуры к поверхности основания кратера и увеличение мощности верхней коры под внешним кольцом кратера (рис. 1). На значительные изменения глубинного строения указывает и структура кратеров. В центре кратера Вредефорт (возраст 2020 млн. лет) выходят архейские гнейсограниты, а платформенные осадки и вулканиты супергрупп Трансвааль и Витватерсранд, бывшие на месте кратера и сохранившиеся вокруг кратера, уничтожены ударом метеорита, их мощность оценивается > 35 км (James et al., 2003).

Другим важным критерием является состав продуктов плавления при взаимодействии импактора и мишени. На химический состав влияют состав мишени, условия $\left(\mathrm{P}, \mathrm{T}^{\circ} \mathrm{C}, \mathrm{fO}_{2}\right)$ плавления, контаминация поднимающегося расплава породой мишени, его последующая дифференциация, примесь материала импактора. На примере структуры Садбери изучена роль контаминации и дифференциации импактного расплава с образованием норит-гранофировой расслоенности (Therriault et al., 2002 и др.). В экспериментах (Шумилова и др., 2018) показана ликвация импактного расплава при сверхвысоких давлениях с обособлением в силикатном стекле углерода и рудного компонента, что представляет интерес, в том числе, при интерпретации рудных скоплений.

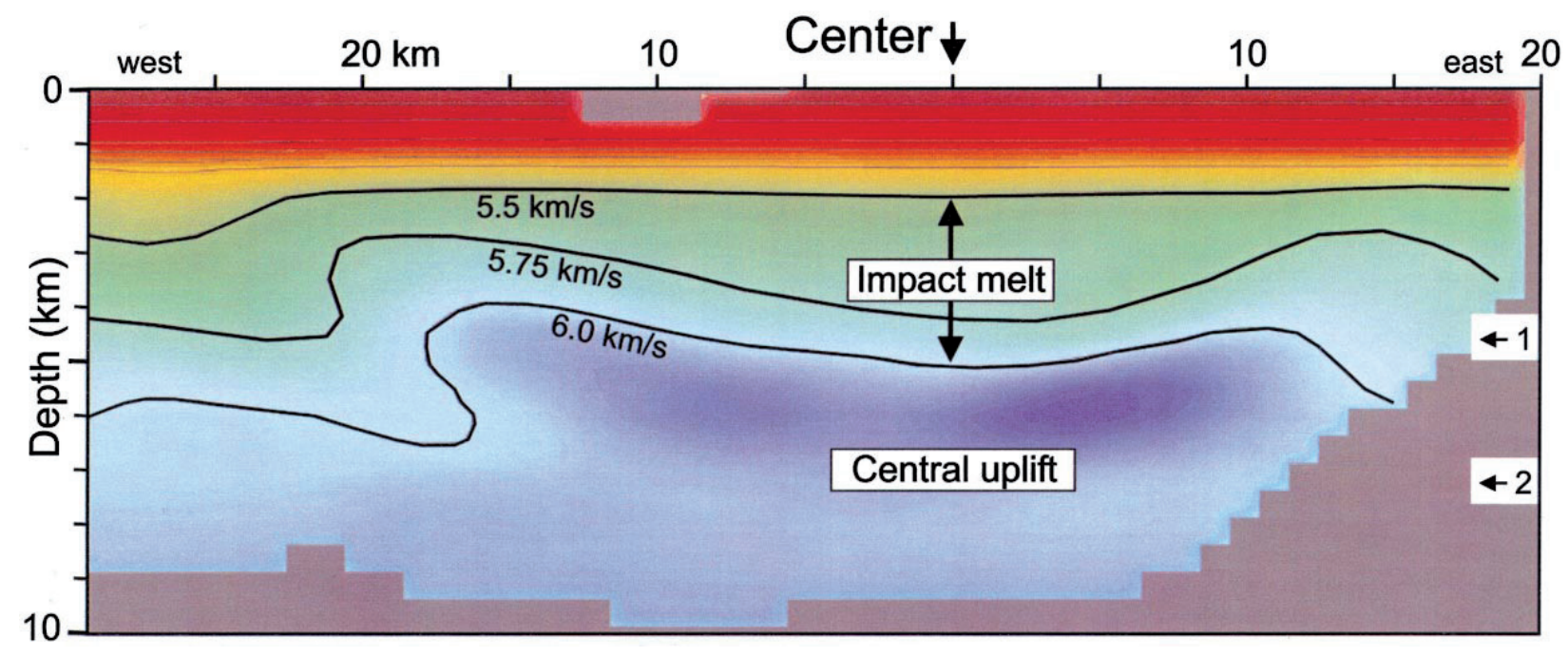

Рис. 1. 2D разрез через трехмерную томограмму сейсмических скоростей через центр кратера Чиксулуб (Morgan et al., 2000).

Fig. 1. A 2D slice through a 3D velocity tomogram across the center of the Chicxulub crater (Morgan et al., 2000). 

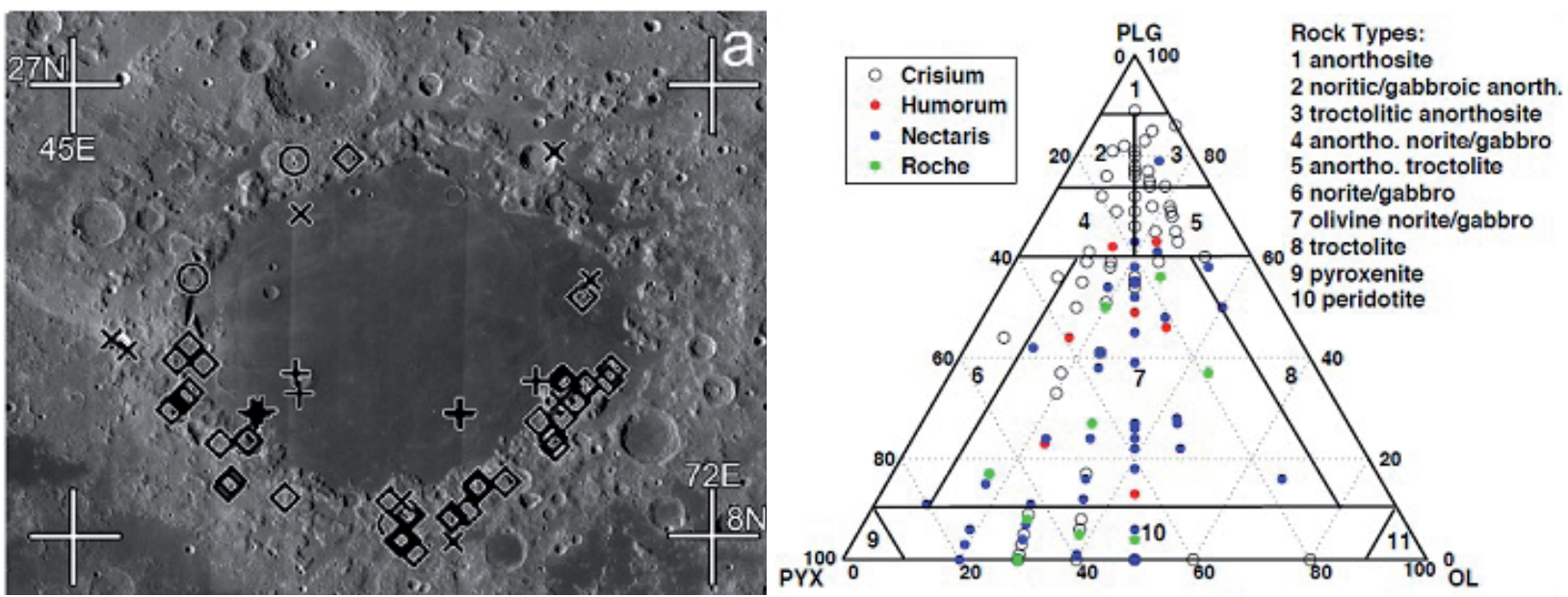

Рис. 2. а - Фотография лунного кратера Crisium. Показано положение составов с оливином разной железистости: X - mg\# 65, $>-\mathrm{mg} \# \sim 90$ (Corley, 2016).

б - вариации составов пород четырех небольших кратеров: Crisium, Humorum, Nectaris и Roche (Corley, 2016).

Fig. 2. a - Photo of the Crisium lunar crater. Rocks with olivine of different iron contents are shown: $\mathrm{X}-\mathrm{mg} \# \sim 65$, $\diamond-\mathrm{mg} \# \sim 90$ (Corley, 2016).

b - variations in rock composition of four small craters: Crisium, Humorum, Nectaris, and Roche (Corley, 2016).

Для определения участия в расплаве вещества импактора используются $\mathrm{Fe}$ и элементы платиновой группы (Palme et al., 1978; Glikson, 2014 и ссылки там), а также изотопный состав элементов (Koeberl et al., 2012). Определение изотопного состава $\mathrm{Cr}$ в хромите сферулы позволило установить, что импактор имел состав углистого хондрита (Kyte et al., 2003). Установление аномалии отношения ${ }^{182} \mathrm{~W} / 184 \mathrm{~W}$ относительно РМ для пород пояса Исуа (ЮЗ Гренландия), древнейших пород Лабрадора и пояса Нувуагиттук (СВ Канады) свидетельствует об участии в их составе метеоритного вещества (Touboul et al., 2014). Время формирования этих пород около 3.8 млрд лет, что поддерживает модель поздней добавки внеземного материала (Late veneer model). Возраст древнейших формаций близок к времени Late Heavy Bombardment (LHB) 3.95-3.85 млрд. лет назад.

На особенности химического состава импактных пород одним из первых обратил внимание В.Л. Масайтис, отметивший обогащение расплава калием по сравнению с породами мишени. В брекчиях Попигайской астроблемы определены химические составы для двух бомб, содержащих в центре мишени - тоналит, окаймленный импактным расплавом состава кварцевого диорита (Masaitis, 1994). Сравнение данных ясно показывает, что расплав, образованный из тоналита, обогащен $\mathrm{K}, \mathrm{Al}, \mathrm{Fe}$. Подобная картина наблюдается для состава конденсата в экспериментах при высоком давлении (Яковлев и др., 1988).

К. Кобером с соавторами (Koeberl et al., 2012) рассмотрены зависимости состава импактитов от различных факторов. В частности, показана связь импактного расплава с размером кратера. Многие особенности импактных расплавов находят объяснение в рамках экспериментов по дифференциации элементов при испарении в результате высокоскоростного удара, имитирующего импактный процесс (Яковлев и др., 1988; Яковлев, Люль, 1992).

\section{Некоторые дискуссионные проблемы геологии, не находящие однозначного объяснения при использовании только эндогенных механизмов}

Одной из важных дискуссионных проблем является состав, время и механизм образования континентальной коры. Ван Тинен с соавторами методом численного моделирования, с учетом высокотемпературных условий и вязкости ранней Земли, показал, что динамика архея была отличной от современной и характеризовалась эпизодами быстрого проникновения больших объемов нижней мантии в верхнюю (Van Thienen et al., 2004). Адекватный вывод получен из анализа изотопных данных (Næraa et al., 2012; Dhuime et al., 2012; Griffin et al., 2014; Вревский и др., 2010), которые пока- 
зали основополагающую роль плюмов в геодинамике Земли и отсутствие до 3.0-3.2 мдрд. лет действия механизма плейт-тектоники.

Согласно модели японских исследователей (ABEL bombardment model - Maruyama, Ebizuzaki, 2017), Земля имела базальт-анортозитовую кору уже 4.55 млрд. лет назад, а 4.37-4.20 млрд. лет назад подверглась бомбардировке, которая явилась триггером субдукции первичной коры. Бомбардировка также сопровождалась привносом биогенных элементов, обеспечивших появление гидросферы и атмосферы. Исходное существование анортозитовой коры согласуется с обнаружением кислого материала на Mapce (Wray et al., 2013).

Большим вкладом в восстановление не сохранившейся ранней коры явилась находка и датирование древнейшего (4.4-3.0 млрд. лет) детритового циркона в осадках Джек Хилс и Маунт Нарриер в Западной Австралии (Compston, Pidgeon, 1986). Данные о строении и составе циркона, изотопии $\mathrm{Hf}$ и $\mathrm{O}^{18}$, минеральных включений $\left(\mathrm{SiO}_{2}\right.$ и KFsp) и температуры кристаллизации привели к выводу об образовании на этапе 4.4-4.5 млрд лет коры гранитного состава (Amelin, 1999; Harrison et al., 2008; Cavoise et al., 2005; Maas et al., 1992; Menneken et al., 2007 и др.) как результат первичной дифференциации (Valley et al., 2006). Высказано предположение, что кора была основного состава, а циркон кристаллизовался из фракционатов гранитоидного состава (Darling et al., 2009). Отмечается возможное происхождение гадейского циркона из дифференцированного импактного расплава (Griffin et al., 2014; Kenny et al., 2016). Возможность образования коры гранитного состава следует из результатов экспериментов по испарению элементов при высокоскоростном ударе в базальтовую мишень. В ходе эксперимента возникает кислый конденсат, который, учитывая огромные масштабы процесса, мог сформировать гранитоидную кору (Яковлев и др., 1988). Присутствие в гадейском цирконе включений $\mathrm{SiO}_{2}$ и KFsp дало основание для заключения о малоглубинном (менее 100 км) происхождении гранитов - источника циркона. Глубинность формирования гранитного расплава стала дискуссионной в связи с обнаружением в цирконе алмаза (Menneken et al., 2007; Nemchin et al., 2008), хотя достоверность их идентификации у некоторых исследователей вызывает сомнение (Dobrzhinetskaya et al., 2014). Детальное изучение структуры алмаза и ее сравнение с другими геологическими типами алмазов (Menneken et al., 2007; Nemchin et al., 2008) убедительно доказывают их магматическое происхождение. Внутреннее строение включений в цирконе, содержащих алмазы (Fig. 5 in Dobrzhinetskaya et al., 2014), в которых обломки алмаза сосуществуют с K-Fsp, находят объяснение в рамках селективного испарения элементов при импакте и соответствует, как отмечено выше, образованию импактных расплавов, обогащенных $\mathrm{K}_{2} \mathrm{O}$ и $\mathrm{Al}_{2} \mathrm{O}_{3}$, что способствует кристаллизации KFsp. Этот механизм объясняет также присутствие включений KFsp в древних зернах циркона на Земле (Lobach-Zhuchenko et al., 2017) и в цирконе лунных брекчий (Liu et al., 2012).

Сохранившиеся реликты гранитоидной коры с возрастом более 3.8 млрд. лет в Гренландии, на Канадском щите и в Антарктиде, имеют тоналит-трондьемитовый состав. Не исключено, что это реликты ранней плагиогранитоидной коры. Двуполевошпатовые граниты, вероятно, являются продуктом дифференциации импактных расплавов или конденсатами селективного испарения элементов в условиях сверхвысоких давлений, возникающих при ударах болидов.

Надо отметить еще две дискуссионные проблемы, которые следует проанализировать, привлекая экстратерригенные процессы: строение гранулитогнейсовых областей, в которых неоднократно метаморфизованные в гранулитовой фации породы выведены на поверхность. Они характеризуются крайней возрастной гетерогенностью, нередко наблюдаемой в одном образце (например, Lobach-Zhuchenko et al., 2017).

Другой проблемой является генезис интрузий необычного состава, типа санукитоидов, или пород с повышенной железистостью. Ниже приведены два рисунка из работы по изучению небольших лунных кратеров (Corley, 2016), которая демонстрирует, что вслед за образованием кратера возникают десятки мелких интрузий, сильно различающихся по железистости (рис. 2 a). Нанесенные на тройную диаграмму составы (рис. 2 б) демонстрируют сосуществование сингенетичных пород широкого спектра составов.

Работа выполнена в рамках тем НИР №№ 0153-2019-0001 и 0226-2019-0052. 


\section{Литература}

1. Вревский А.Б., Лобач-Жученко С.Б., Чекулаев В.П., Коваленко А.В., Арестова Н.А. Петрологогеодинамические условия образования тоналит-трондъемит-гранодиоритовых ассоциаций и формирование континентальной коры древних кратонов // Геотектоника. 2010. Т. 44. № 4. С. 20-38.

2. Кузьмин М.И., Яромолюк В.В., Эрнст Р. Тектоническая активность Земли на ранних этапах (4.56-3.4 (2.7?)) ее эволюции // Геология и геофизика. 2016. № 5. С. 815-832.

3. Масайтис ВЛ., Михайлов М.В., Селивановская Г.В. Попигайский метеоритный кратер. Москва: Наука, 1975. 124 с.

4. Шумилова Т.Г., Исаенко С.И., Макеев Б.А., Зубов А.А., Шанина С.Н. и др. Ультравысокобарная ликвация импактного расплава // ДАН. 2018. Т. 480. № 1. С. 90-93. DOI:10.7868/s0869565218130182.

5. Я Яковлев О.И., Файнберг В.С., Казначеев Е.А., Пилюгин Н.Н., Баулин Н.Н. и др. Экспериментальное изучение испарения при высокоскоростном ударе // Геохимия. 1988. № 12. С. 1698-1707.

6. Яковлев О.И., Люль А.Ю. Геохимия микроэлементов в ударном процессе // Геохимия. 1992. № 3 C. 323-337.

7. Amelin Y., Lee D-Ch., Halliday A., Pidgeon R. Nature of the Earth's earliest crust from hafnium isotopes in single detrital zircons // Nature. 1999. V. 399. P. 252-255. DOI: 10.1038/20426.

8. Cavosie A.J., Valley J.W. Wilde S.A. Magmatic $\delta 180$ in 4400-3900 Ma detrital zircons: a record of the alteration and recycling of crust in the Early Archean // Earth Planet. Sci. Lett. 2005. V. 235. P. 663-681.

9. Compston W., Pidgeon R.T. Jack Hills, evidence of more very old detrital zircons in Western Australia // Nature. 1986. V. 321. P. 766-769.

10. Corley L.M. Lunar olivine exposures: origins and mechanisms of transport. A final report for the degree of master of science in geology and geophysics. Department of geology and geophysics. University of Hawai ${ }^{i} \mathrm{i}$ at Mānoa. 2016. 13 p.

11. Darling J., Storey C., Hawkesworth C. Impact melt sheet zircons and their implications for the Hadean crust // Geology. 2009. V. 73. P. 927-930. DOI: 10.1130/G30251A.1.

12. Dhuime B., Hawkesworth C., Storey C. A change in geodynamics continental growth 3 billion years ago // Science. 2012. V. 335. Is. 6074. P. 1334-1336. DOI: 10.1126/science.1216066.

13. Dobrzhinetskaya L., Wirth R., Green H. Diamonds in Earth's oldest zircons from Jack Hills conglomerate, Australia, are contamination // Earth and Planetary Science Letters. 2014. V. 387. P. 212-218. DOI: $10.1016 /$ j.epsl.2013.11.023.

14. Garde A.A., McDonald I., Dyck B., Keulen N. Searching for giant, ancient impact structures on Earth: The Mesoarchaean Maniitsoq structure, West Greenland // Earth and Planetary Sci. Lett. 2012. V. 337-338. P. 197-210.

15. Glikson A.Y. Geochemical and isotopic signatures of Archaean to early Proterozoic extraterrestrial impact ejecta/fallout units // Aust J Earth Sci. 2005. V. 52. P. 785-799.

16. Glikson A.Y. The Archaean: Geological and Geochemical Windows into the Early Earth. 2014. Springer. 238 p.

17. Glikson A.Y. The asteroid impact connection of planetary evolution. 2013. Springer-Briefs, Dordrecht, 150 p. DOI: $10.1007 / 978-94-007-6328-9$.

18. Glikson A., Hickman A., Evans N., Kirkland C., Park J. et al. A new 3.46 Ga asteroid impact ejecta unit at Marble Bar, Pilbara Craton, Western Australia: A petrological, microprobe and laser ablation ICPMS study // Precambrian Research. 2016. V. 279. P. 103-122. DOI:10.1016/j.precamres.2016.04.003.

19. Griffin W.L., Belousova E., O’Neill C., O'Reilly S., Malkovets V. et al. The world turns over: Hadean-Archean crust-mantle evolution // Lithos. 2014. V. 189. P. 2-15. DOI: 10.1016/j.lithos.2013.08.018.

20. Harrison T.M., Schmitt A.K., McCulloch M.T., Lovera O.M. Early (4.5 Ga) formation of terrestrial crust: Lu-Hf, 8O, and Ti thermometry results for Hadean zircons // Earth and Planetary Sci. Lett. 2008. V. 268. P. 476-486.

21. James D. E., Niu F., Rokosky J. Crustal structure of the Kaapvaal craton and its significance for early crustal evolution // Lithos. 2003. V. 71. P. 413- 429.

22. Kenny G.G., Whitehouse M.J., Kamber B.S. Differentiated impact melt sheets may be a potential source of Hadean detrital zircon // Geology. 2016. V. 44. No 6. P. 435-438. doi:10.1130/G37898.1.

23. Koeberl C. The record of impact processes on the early Earth: A review of the first 2.5 billion years. In: Reimold WU, Gibson RL (eds) Processes on the Early Earth. Geological Society of America, Boulder, Special Paper. 2006. V. 405. P. 1-22.

24. Koeberl C., Claeys P., Hecht L., McDonald I. Geochemistry of impactites // Elements. 2012. V. 8. P. 37-42.

25. Kyte F., Shukloyukov A., Lugmair G., Lowe D., Byerly G. Early Archean spherule beds: Chromium isotopes confirm origin through multiple impacts of projectiles of carbonaceous chondrite type // Geology. 2003. V. 31. P. 283-286. 
26. Liu, D., Jolliff B.L., Zeigler R.A., Korotev R.L., Wan Y., Xie H. et al. Comparative zircon U-Pb geochronology of impact melt breccias from Apollo 12 and lunar meteorite SaU 169, and implications for the age of the Imbrium impact // Earth and Planetary Sci. Lett. 2012. V. 319-320. P. 277-286. DOI:10.1016/j.eps1.2011.12.014.

27. Byerly G.R., Lowe D.R., Wooden J.L., Xie X. An Archean Impact Layer from the Pilbara and Kaapvaal Cratons // Science. 2002. V. 297. DOI:10.1126/science.1073934.

28. Lobach-Zhuchenko S.B., Kaulina T.V., Baltybaev S.K., Balagansky V.V., Egorova Yu.S. et al. The long (3.7-2.1 Ga) and multistage evolution of the Bug Granulite-Gneiss Complex, Ukrainian Shield, based on the SIMS U-Pb ages and geochemistry of zircons from a single sample. Geological Society, London, Special Publications. 2017. V. 449. P. 175-206. http://doi.org/10.1144/SP449.3.

29. Lyapidevskaya Z.A., Gusiakov V.K. Catalog and database on the Earth impact structures. Bull. Nov. Comp. Center, Math. Model. in Geoph. 2010. V. 13. P. 79-91.

30. Maas R., Kinny P.D., Williams I.S., Froude D.O., Comston W. The Earth's oldest known crust: a geochronological and geochemical study of 3900-4200 Ma old detrital zircons from Mt Narryer and Jack Hills, Western Australia // Geochim. Cosmochim. Acta. 1992. V. 56. P. 1281-1300.

31. Maruyama S., Ebisuzaki T. Origin of the Earth: a proposal of new model called ABEL // Geoscience Frontiers. 2017. V. 8. No 2. P. 253-274. doi: 10.1016/j.gsf.2016.10.005.

32. Masaitis V.L. Impactites from Popigai crater, in: B.O. Dressler, R.A.F. Grieve, V.L. Sharpton (Eds.), Large Meteorite Impacts and Planetary Evolution, Geol. Soc. Am. Spec. Pap. 1994. V. 293. P. 152-162.

33. McCall C.J.H. Half a century of progress in research on terrestrial impact structures: a review // Earth Science Reviews. 2009. V. 92. P. 99-116.

34. Menneken M., Nemchin A., Geisler T., Pidgeon R., Wilde S. Hadean diamonds in zircon from Jack Hills, Western Australia // Nature. 2007. V. 448. P. 917-920. DOI:10.1038/nature06083.

35. Morgan J., Warner M., Collins G.et al. Peak-ring formation in large impact craters: geophysical constraints from Chicxulub // Earth and Planetary Sci. Lett. 2000. V. 183. P. 347-354.

36. Nemchin A., Whitehouse M., Menneken M., Geisler T., Pidgeon R., Wilde S. A light carbon reservoir recorded in zircon-hosted diamond from the Jack Hills // Nature. 2008. V. 454. P. 92-95. DOI:10.1038/nature07102.

37. Næraa T., Schersten A., Rosing M., Kemp A., Hoffman J. et al. Hafnium isotope evidence for a transition in the dynamics of continental growth 3.2Ga ago // Nature. 2012. V. 485. P. 627-630. DOI:10.1038/nature11140.

38. Palme H., Janssens M. J., Takahasi H., Anders E., and Hertogen J. Meteorite material at five large impact craters // Geochimica et Cosmochimica Acta. 1978. V. 42. P. 313-323.

39. Reimold W.U., Jourdan F. Impact! - Bolides, craters, and Catastrophes // Elements. 2012. V. 8. P. 19-24.

40. Reimold W.U, Gibson R.L. (eds) Processes of the Early Earth: Geological Society of America Special Paper. 2006. V. 405. P. 22-31.

41. Therriault A.M., Fowler A.D., Grieve R.A.F. The Sudbury Igneous Complex: A Differentiated Impact Melt Sheet // Economic Geology. 2002. V. 97. P. 1521-1540.

42. Touboul M., Liu J., O’Neil J., Puchtel I., Walker R. New insights into the Hadean mantle revealed by $182 \mathrm{~W}$ and highly siderophile element abundances of supracrustal rocks from the Nuvvuagittuq Greenstone Belt, Quebec, Canada // Chemical Geology. 2014. V. 383. P. 63-75. DOI:10.1016/j.chemgeo.2014.05.030.

43. Valley J.W., Cavosie A., Wilde S. What have we learned from pre-4 Ga zircons? // Geochim Cosmochim Acta. 2006. V. 70. Doi:10.1016/j.gca.2006.06.1241.

44. Van Thienen P., van den Berg A.P., Vlaar N.J. Production and recycling of oceanic crust in the early Earth // Tectonophysics. 2004. V. 386. P. 41-65. Doi:10.1016/j.tecto.2004.04.027.

45. Wray J., Hansen S., Dufek J. Swayze G., Murchie S. et al. Prolonged magmatic activity on Mars inferred from the detection of felsic rocks // Nature Geoscience. 2013. V. 6. P. 1013-1017. Doi: 10.1038/ngeo1994. 